has heeded Bush's call for biological as well as mathematical models in computer science or his concerns about the influence of corporations on the growth of the field. Wright shows more generally how the Internet has developed beyond the control or the approval of its early contributors (such as Tim Berners-Lee or Ted Nelson, the conceptual father of hypertext).

The historical perspective of Glut is admirable: Wright neither assumes a linear progress nor makes unwarranted claims about the novelty or the indebtedness of current technologies to earlier ones. He doesn't try to predict what the lasting impacts of the Web will be, but notes that the Internet facilitates the formation of small, self-organized communities that have the potential to undermine large hierarchical structures. In this way, he suggests that human culture may no longer be moving unidirectionally as was once thought, towards coalescence into larger entities, but rather multidirectionally. Wright clearly values the growth of grassroots self-organization on the Web, but also acknowledges that bottom-up networks can benefit from some hierarchical structure.

One pay-off of attending to earlier ambitions for information control is to highlight some of the weaknesses of our current system. Wright notes, for example, that our search algorithms and the metadata they create are not transparent but are the work of software engineers operating within a world of commercial secrecy; and our weblinks that carry information about intellectual associations are evanescent and can disappear without leaving a trace. Using the analogy of print's arrival in the mid-fifteenth century, Wright warns of the potential for new technologies to seriously disrupt established structures. However, his interpretation that printing caused the Protestant Reformation is overly reductionist.

Wright's conclusion that "as Internet users continue to congregate in small groups, such behavior harkens back to our deepest rooted social instincts" is less convincing. This type of hasty sociobiological generalization argues from evidence selected to suit its purposes, without weighing counterevidence or other contributing factors. That humans have evolved a desire to communicate and form social groups does not strike me as the most helpful explanation for the complex choices we make among the many means of communication now at our disposal. Indeed, Wright shows throughout his book how the tools that were developed in different historical contexts to cope with information overload continue to shape our options and ambitions today.

This stimulating book offers much opportunity to reflect on the nature and long history of information management as a damper to the panic or the elation we may variously feel as we face ever greater scales of information overload.

Ann Blair is a professor of history at Harvard University, Cambridge, Massachusetts 02138, USA.

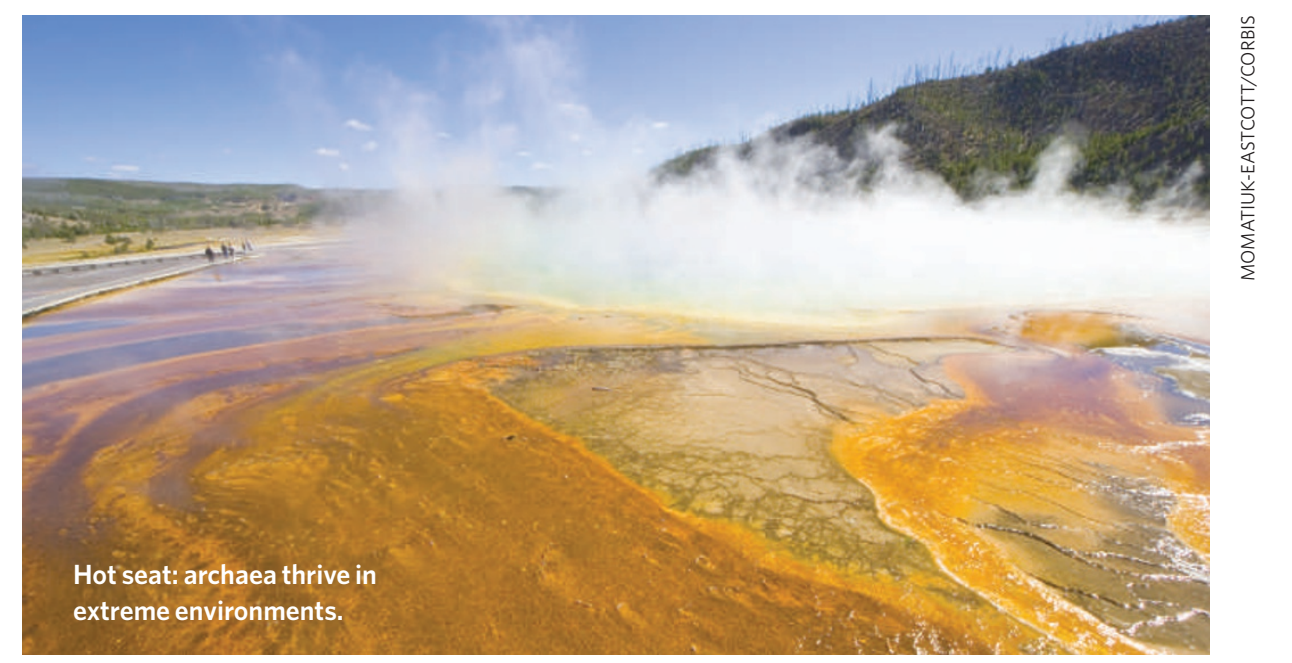

\title{
Introducing the extremophiles
}

\section{The Third Domain: The Untold Story of Archaea and the Future of Biotechnology by Tim Friend \\ Joseph Henry Press: 2007. 250 pp. \$27.95}

\section{Sean Nee}

Envy the achievement of Carl Woese, who announced his discovery of the third domain of life on Earth a mere 30 years ago. Marvel at the fact that most people are unaware of this three-domain understanding of biodiversity. Admire the journalist Tim Friend who resigned from the newspaper USA Today to write this superb book introducing the public to the third domain. Buy it and enjoy the personalities, the adventures, the drama and the science too, all presented in an admirable mix that is a terrific read.

Until recently, our view of life on Earth had changed little over centuries. There were animals, plants and a bunch of little things such as bacteria. One of the many quaint anachronisms of the University of Oxford is that it is still one of the few seats of learning to have separate departments of plant sciences and zoology, reflecting a view of life that is as outdated as snuff after dinner and bulldogs in bowler hats (don't ask). It is probably no coincidence that Oxford's most famous popular writer on biology, Richard Dawkins, notoriously gave only a single page to the third domain of life in his take on biodiversity, The Ancestor's Tale, apparently more interested in things like cabbages.

Here are the three domains. Bacteria: you know what they are but you probably have no idea how interesting they are - but that's another book. Eukaryotes: unlike bacteria, eukaryotic cells enclose their genetic material in an internal membrane and have lots of internal membrane-bound organelles. This domain includes multicellular plants and animals, but these are small beer compared with the enormous diversity of single-celled eukaryotes, most of which we know about only because they cause disease, such as giardia. The third domain, the subject of this book, is the archaea. Although they are single-celled and definitely not eukaryotes, they are not bacteria either. To see this point clearly, know that there are no archaea that cause disease. If anyone has a good idea why this is, please contact me at once. It is not that they are only found in strange places where we do not go - your mouth, for example, is teeming with them. Also, a particular antibiotic that works by disrupting the information-processing machinery in bacteria has no effect on eukaryotes or archaea. The current understanding is that we share the same information-processing genes as archaea.

It had long been conventional wisdom that the phylogeny - the family tree - of bacteria could not be constructed. Until recently, phylogenies had been based on morphology: we look quite like gorillas and chimps, less like gibbons, even less like howler monkeys, not at all like cabbages, and so on. These degrees of similarity reflect the length of our separation in evolutionary time. But morphology is useless for bacteria: they are blobs, squiggles or rods. That tells us nothing.

Soon after the invention of DNA-sequencing technologies, Carl Woese had the insight that comparing sequence similarities between bacteria might allow the construction of their phylogeny, and he got to work. He chose a particular gene that is essential in translating DNA into proteins and so must be found in all life forms - at least, as understood at the time. Having sequenced a segment of the gene in many bacterial species and found reasonably varying degrees of similarity, a colleague down the hall brought him some 'bacteria' with an unusual metabolism: methanogens get their energy by combining hydrogen and carbon dioxide, producing the potent greenhouse gas methane as an end product. These are responsible for swamp gas, for example, and about $50 \%$ of you reading this have them in your gut. This is one of the gases that allows you to do 
your party trick, bent over, with a lighter in a darkened room. Woese found that the methanogen gene sequence was very, very different to those of other bacteria he had sequenced. What could this mean?

At the time, and before, microbiologists had been looking for life in apparently ridiculous places, and finding it. We now know that archaea can live everywhere: in hot acid fluids that can dissolve steel, in fluids as alkaline as those we use for floor strippers, in pressures and temperatures as high as that in autoclaves that hospitals use to sterilize equipment. It is not just that they can tolerate such environments. These are their natural habitats and species adapted to them die in conditions that we would consider benign. Sequencing more and more such 'extremophiles' from different environments, Woese found that they all naturally grouped together in the 'bacterial' family tree.

Previous workers, such as the exalted Thomas Brock, had observed that the biochemistry of the cell walls of 'bacteria' was similar in specimens from very different extreme environments and quite different from that of typical bacteria. This had been explained away as convergent evolution - the same adaptation by bacteria to extreme environments, of whatever sort. But Woese pulled all the evidence together and made the intellectual leap that is now accepted: there is a third domain of life - the archaea.
All of this is told, and much more. Friend quite rightly does not restrict himself to archaea. For example, there is a fascinating chapter on the Titanic, which is literally being eaten by enormous, macroscopic consortia of symbiotic microbes from all three domains superorganisms called rusticles with vasculatures and immune systems, ultimately powered by the fact that the sunken passenger liner is functioning like a giant battery. Having learned all about them from the scientists, Friend went down to the Titanic to see for himself. I'd quit my job for that as well.

Sean Nee is an evolutionary biologist at the School of Biological Sciences, University of Edinburgh, Edinburgh EH9 3JT, UK.

\section{Mind tricks}

\section{Cognitive scientists take a lesson from magicians.}

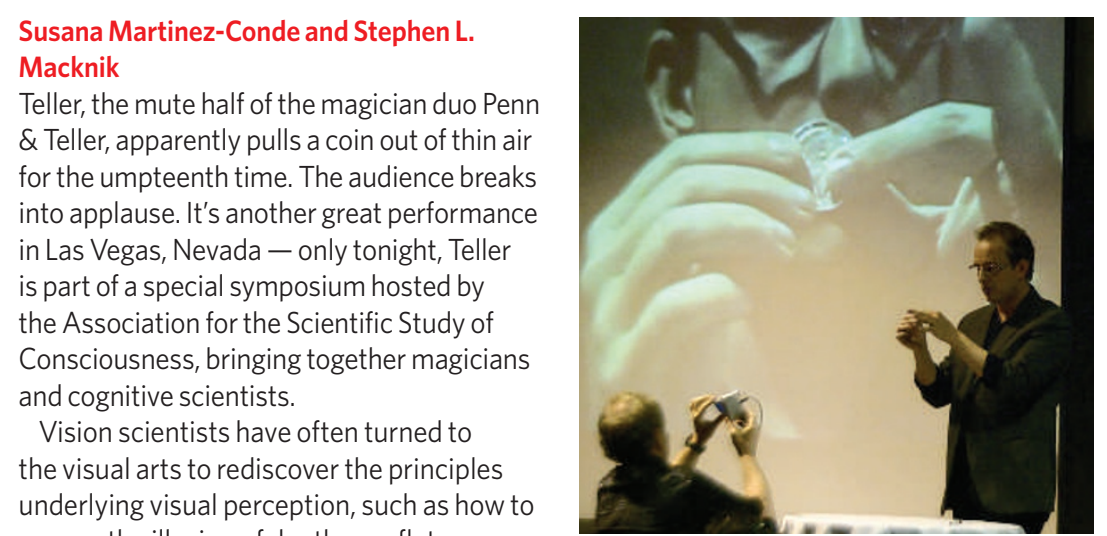

convey the illusion of depth on a flat canvas. Similarly, cognitive scientists have much to learn from magicians, who have developed cognitive principles and illusions that trick audiences.

The Magic of Consciousness Symposium on 24 June attempted to plumb directly the depths of the intuition of world-class magicians. Magicians are behaviour experts who artfully manipulate attention and awareness. Their wealth of knowledge on cognition and behaviour is now ripe for picking.

James Randi - aka The Amaz!ng Randi — explained that spectators will easily accept unspoken assumptions. He made his point by fooling more than 200 consciousness researchers into thinking that his voice was being amplified by a dummy microphone, and by pretending to read with glasses that were merely empty frames.

Teller pulled coins out of thin air, conference bags and spectacles. He used water from his drinking glass to make a ball disappear. Shedding his normally silent stage persona, he described with eloquence how magicians make their audiences incorrectly link cause and effect. We all infer cause and effect in everyday life. When $A$ time he changed the method, deceiving the audience once again. "Much of our lives is devoted to understanding cause and effect," Teller said. "Magic provides a playground for those rational skills."

He also explained that "action is motion with a purpose". In normal social interactions, we constantly search for the purpose motivating other people's actions. An action with no obvious purpose raises questions. However, when the purpose seems crystal clear, we look no further. "Skilled magicians inform every necessary maneuver (motion) with a convincing intention," said Teller.

Thus, the real purpose of the motion (hiding the ball) is hidden by the apparent purpose of the action (pouring the water).

Apollo Robbins, a professional thief who once pickpocketed Jimmy Carter's secret service detail, demonstrated the use of interpersonal distance and eye contact to control a target's gaze and attention. In doing so, he looted, undetected, every single pocket of a journalist from the audience.

James Randi tied the evening together by effortlessly escaping ropes knotted by philosopher Dan Dennett. The intuitive insights offered by magicians will frame future cognitive experiments, from measuring the dynamics of attentional blindness to determining the neural correlates of causal inference. Where in the brain is motion perceived as action? Does this same brain area encode the purpose of the action? For cognitive scientists, the second act of the show will take place in the lab.

Susana Martinez-Conde and Stephen L. Macknik are at the Barrow Neurological Institute of St Joseph's Hospital and Medical Center, Phoenix, Arizona 85013, USA. They co-chaired the 11th Annual Meeting of the Association for the Scientific Study of Consciousness. 